\title{
Aortic Angiosarcoma
}

National Cancer Institute

\section{Source}

National Cancer Institute. Aortic Angiosarcoma. NCI Thesaurus. Code C5376.

A malignant vascular neoplasm arising from the aorta. 